\title{
In Vivo VEGF Imaging with Radiolabeled Bevacizumab in a Human Ovarian Tumor Xenograft
}

\author{
Wouter B. Nagengast ${ }^{1}$, Elisabeth G. de Vries ${ }^{1}$, Geke A. Hospers ${ }^{1}$, Nanno H. Mulder ${ }^{1}$, Johan R. de Jong ${ }^{2}$, Harry Hollema ${ }^{3}$, \\ Adrienne H. Brouwers ${ }^{2}$, Guus A. van Dongen ${ }^{4}$, Lars R. Perk ${ }^{4}$, and Marjolijn N. Lub-de Hooge ${ }^{2,5}$ \\ ${ }^{I}$ Department of Medical Oncology, University of Groningen and University Medical Center Groningen, Groningen, The Netherlands; \\ ${ }^{2}$ Department of Nuclear Medicine and Molecular Imaging, University of Groningen and University Medical Center Groningen, Groningen, \\ The Netherlands; ${ }^{3}$ Department of Pathology, University of Groningen and University Medical Center Groningen, Groningen, The \\ Netherlands; ${ }^{4}$ Department of Nuclear Medicine and PET Research, VU Medical Center, Amsterdam, The Netherlands; and ${ }^{5}$ Department \\ of Hospital and Clinical Pharmacy, University of Groningen and University Medical Center Groningen, Groningen, The Netherlands
}

Vascular endothelial growth factor (VEGF), released by tumor cells, is an important growth factor in tumor angiogenesis. The humanized monoclonal antibody bevacizumab blocks VEGFinduced tumor angiogenesis by binding, thereby neutralizing VEGF. Our aim was to develop radiolabeled bevacizumab for noninvasive in vivo VEGF visualization and quantification with the single $\gamma$-emitting isotope ${ }^{111} \mathrm{In}$ and the PET isotope ${ }^{89} \mathrm{Zr}$. Methods: Labeling, stability, and binding studies were performed. Nude mice with a human SKOV-3 ovarian tumor xenograft were injected with ${ }^{89} \mathrm{Zr}$-bevacizumab, ${ }^{111} \mathrm{In}$-bevacizumab, or human ${ }^{89} \mathrm{Zr}$-lgG. Human ${ }^{89} \mathrm{Zr}$-IgG served as an aspecific control antibody. Small-animal PET and microCT studies were obtained at 24, 72, and $168 \mathrm{~h}$ after injection of $89 \mathrm{Zr}$-bevacizumab and ${ }^{89} \mathrm{Zr}-\operatorname{lgG}(3.5 \pm 0.5 \mathrm{MBq}, 100 \pm 6 \mu \mathrm{g}, 0.2 \mathrm{~mL}$ [mean $\pm \mathrm{SD}$ ]). Small-animal PET and microCT images were fused to calculate tumor uptake and compared with ex vivo biodistribution at $168 \mathrm{~h}$ after injection. ${ }^{89} \mathrm{Zr}$ - and ${ }^{111} \mathrm{In}$-bevacizumab ex vivo biodistribution was compared at 24,72 , and $168 \mathrm{~h}$ after injection $(2.0 \pm$ $0.5 \mathrm{MBq}$ each, $100 \pm 4 \mu \mathrm{g}$ in total, $0.2 \mathrm{~mL}$ ). Results: Labeling efficiencies, radiochemical purity, stability, and binding properties were optimal for the radioimmunoconjugates. Small-animal PET showed uptake in well-perfused organs at $24 \mathrm{~h}$ and clear tumor localization from $72 \mathrm{~h}$ onward. Tumor uptake determined by quantification of small-animal PET images was higher for $89 \mathrm{Zr}$-bevacizumab-namely, $7.38 \pm 2.06 \% \mathrm{ID} / \mathrm{g}$ compared with $3.39 \pm 1.16 \% \mathrm{ID} / \mathrm{g}$ (percentage injected dose per gram) for human ${ }^{89} \mathrm{Zr}-\operatorname{lgG}(P=0.011)$ at $168 \mathrm{~h}$ and equivalent to ex vivo biodistribution studies. Tracer uptake in other organs was seen primarily in liver and spleen. ${ }^{89} \mathrm{Zr}$ - and ${ }^{111} \mathrm{In}$-bevacizumab biodistribution was comparable. Conclusion: Radiolabeled bevacizumab showed higher uptake compared with radiolabeled human IgG in a human SKOV-3 ovarian tumor xenograft. Noninvasive quantitative small-animal PET was similar to invasive ex vivo biodistribution. Radiolabeled bevacizumab is a new tracer for noninvasive in vivo imaging of VEGF in the tumor microenvironment.

Received Feb. 28, 2007; revision accepted Apr. 20, 2007.

For correspondence or reprints contact: Elisabeth G. de Vries, MD, PhD, Department of Medical Oncology, University Medical Center Groningen, P.O. Box 30.001, 9700 RB Groningen, The Netherlands.

E-mail: e.g.e.de.vries@int.umcg.nl

COPYRIGHT @ 2007 by the Society of Nuclear Medicine, Inc.
Key Words: VEGF; bevacizumab; small-animal PET; xenograft; in vivo

J Nucl Med 2007; 48:1313-1319

DOI: 10.2967/jnumed.107.041301

O growth of tumors. Angiogenesis, the forming of new blood vessels, is one of these factors. New vasculature allows tumor cells to execute their critical growth by supplying the tumor with nutrients and oxygen, enabling disposal of metabolic waste products and providing a route for metastatic spreading $(1,2)$. An important factor involved in angiogenesis is vascular endothelial growth factor A (hereafter referred as VEGF) (3). VEGF consists of at least 4 splice variants, containing 121, 165, 189, and 206 amino acids (3). It is produced by tumor cells and induces tumor neovascularization (4-7).

Overexpression of VEGF occurs in many human tumor types, which makes VEGF a rational target for antiangiogenic therapy $(8-11)$. This has led to interest in blocking the signaling of VEGF in human tumors. Antibodies binding to this ligand and its receptors, and chemical molecules that can block the tyrosine kinase function of VEGF receptors, have been developed (12).

The drug that is currently most widely used in the clinic is the humanized monoclonal antibody bevacizumab. It blocks VEGF-induced endothelial cell proliferation, permeability, and survival, and it inhibits human tumor cell line growth in preclinical models $(8,13-15)$. The likely mechanism is that bevacizumab binds to VEGF-both soluble and bound to the extracellular matrix - and thereby prevents VEGF binding to its receptors, blocking the biologic pathways induced after VEGF binding. Bevacizumab is approved for clinical use in metastatic colon carcinoma and non-small cell lung cancer (16,17). Approval for several other tumor types is expected soon. 
Despite the success of antiangiogenic therapy, a large percentage of patients does not benefit from this targeted therapy. Currently, it is impossible to predict which patient will benefit from antiangiogenic therapy. Reasons for treatment failure may be that the target for the drug is not present or that the drug may not reach the target. Tumor cells produce VEGF, which can lead to paracrine effects in the microenvironment. $\mathrm{VEGF}_{121}$ is freely soluble, whereas VEGF $_{165}$ is secreted, though a significant fraction remains localized to the extracellular matrix, such as $\mathrm{VEGF}_{189}$ and $\mathrm{VEGF}_{206}$ (18). This will most likely lead to locally high VEGF levels. It is currently impossible to evaluate these local VEGF levels (19). Noninvasive measurement of VEGF in the tumor might give insight to the available target for VEGF-dependent antiangiogenic therapy and thus assist in tumor response prediction. To allow in vivo VEGF imaging, we set up bevacizumab labeling with the relatively new long-lived PET isotope ${ }^{89} \mathrm{Zr}$ and the widely available single $\gamma$-emitting isotope ${ }^{111}$ In (20-23).

In the present study, we describe the development and the in vivo evaluation of ${ }^{89} \mathrm{Zr}$-bevacizumab and ${ }^{111} \mathrm{In}$-bevacizumab in a tumor-bearing mouse model and compare noninvasively obtained in vivo ${ }^{89} \mathrm{Zr}$-bevacizumab and ${ }^{89} \mathrm{Zr}$ - $\operatorname{lgG}$ imaging quantification data with ex vivo biodistribution data.

\section{MATERIALS AND METHODS}

\section{Conjugation and ${ }^{89} \mathrm{Zr}$ Labeling of Bevacizumab and Control IgG}

Bevacizumab (Avastin, $25 \mathrm{mg} / \mathrm{mL}$; Roche) and human IgG (Immunoglobuline I.V.; Sanquin) conjugation and labeling were performed as described previously by Verel et al. (22). Human IgG served as an aspecific control antibody. Briefly, bevacizumab and $\operatorname{IgG}$ were purified from other excipients by ultrafiltration (Vivaspin-2; Sartorius) and diluted in water for injection to 5 $\mathrm{mg} / \mathrm{mL}$. Hereafter, conjugation of purified bevacizumab and $\mathrm{IgG}$ was achieved using $N$-succinyldesferrioxamine B-tetrafluorphenol ( $N$-sucDf-TFP; VU Medical Center). The ester and the antibodies (bevacizumab and human $\mathrm{IgG}$ ) were conjugated at room temperature for $30 \mathrm{~min}$ at $\mathrm{pH} 9.5-9.7\left(0.1 \mathrm{~mol} / \mathrm{L} \mathrm{Na}_{2} \mathrm{CO}_{3}\right.$; Bufa) with $1.5-2.5$ chelate groups per antibody molecule. After conjugation, the mixture was set to $\mathrm{pH} 4.2-4.4\left(0.1 \mathrm{~mol} / \mathrm{L} \mathrm{H}_{2} \mathrm{SO}_{4}\right.$; University Medical Center Groningen [UMC Groningen]), and $50 \mu \mathrm{L}$ of 25 $\mathrm{mg} / \mathrm{mL}$ ethylenediaminetetraacetic acid (EDTA; Calbiochem) were added. The solutions were incubated $30 \mathrm{~min}$ at $35^{\circ} \mathrm{C}$ and again purified by ultrafiltration, diluted in water for injection ( 5 $\mathrm{mg} / \mathrm{mL}$ ), and stored at $-20^{\circ} \mathrm{C}$.

Labeling was performed with ${ }^{89} \mathrm{Zr}$ (half-life $=3.27 \mathrm{~d}$ ) produced by Cyclotron $\mathrm{BV}$, which was delivered as ${ }^{89} \mathrm{Zr}$-oxalate dissolved in oxalic acid (1 $\mathrm{M}$ oxalic acid, $2 \mathrm{GBq} / \mathrm{mL}, 4 \mathrm{GBq} / \mu \mathrm{g}$ ${ }^{89} \mathrm{Zr}$, $99.9 \%$ radionuclidic purity). In brief, the ${ }^{89} \mathrm{Zr}$-oxalate solution was set at $\mathrm{pH} 3.9-4.2$ and mixed for 3 min and was adjusted to $\mathrm{pH}$ 6.7-6.9 with 4-(2-hydroxyethyl)-1-piperazineethanesulfonic acid (HEPES; Sigma-Aldrich) buffer. $N$-sucDf-bevacizumab was added and incubated for $45 \mathrm{~min}$ at room temperature.

\section{Conjugation and ${ }^{111}$ In Labeling of Bevacizumab}

Bevacizumab was conjugated with the chelator 2-(4-isothiocyanatobenzyl)-diethylenetriaminepentaacetic acid (ITC-DTPA;
Macrocyclics) according to Ruegg et al. (24) with 2 or 3 chelate groups per antibody molecule. Briefly, $5 \mathrm{mg}$ purified bevacizumab were adjusted to $\mathrm{pH} 9.2-9.5$ (50 mmol/ $\mathrm{L} \mathrm{Na}_{2} \mathrm{CO}_{3}, \mathrm{pH}$ 9.5; Bufa) and $50 \mathrm{M}$ excess ITC-DTPA was added. After a 1-h incubation at room temperature, the reaction mixture was purified by ultracentrifugation with ammonium acetate $(50 \mathrm{mmol} / \mathrm{L}$; UMC Groningen), $\mathrm{pH} 5.5$, to eliminate the excess unconjugated ITC-DTPA. Purified conjugated bevacizumab was diluted $(5 \mathrm{mg} / \mathrm{mL})$ in ammonium acetate and stored at $-20^{\circ} \mathrm{C}$. Labeling was performed with $1 \mathrm{mg}$ of purified ITC-DTPA-bevacizumab, which was allowed to react with $50 \mathrm{MBq}$ of ${ }^{111} \mathrm{InCl}_{3}(370 \mathrm{MBq} / \mathrm{mL},>1.85$ $\mathrm{GBq} / \mu \mathrm{g}{ }^{111} \mathrm{In}, 99.9 \%$ radionuclidic purity; Tyco Health Care) for $1 \mathrm{~h}$ at room temperature. Glassware, materials, and solutions used for the conjugation and labeling procedures were sterilized, pyrogen-free, and metal-free.

\section{Quality Control of ${ }^{89} \mathrm{Zr}$-Bevacizumab, ${ }^{111}$ In-Bevacizumab, and ${ }^{89} \mathrm{Zr}$-IgG}

The radiochemical purity of the radiolabeled antibodies was determined by size-exclusion high-performance liquid chromatography (SE-HPLC), trichloroacetic acid protein precipitation (TCA) ( ${ }^{89} \mathrm{Zr}$-antibodies), and instant thin-layer chromatography (ITLC) $\left({ }^{111}\right.$ In-bevacizumab) to differentiate the labeled product from aggregates and unlabeled ${ }^{89} \mathrm{Zr}$ and ${ }^{111} \mathrm{In}$.

The HPLC system used consisted of a Waters 1500 series manual injector with a $20-\mu \mathrm{L}$ injection loop (Rheodyne $7725 \mathrm{i}$ injector; Milford), a Waters 1525 binary HPLC pump, a Waters 2487 dual-wavelength absorbance detector, and an in-line radioactivity detector made of a sodium iodide crystal coupled to a multichannel analyzer (Ortec). Chromatograms were analyzed using the Breeze software (Waters). A Superdex 200 30/300 GL size-exclusion column (Amersham Biosciences) was used. The mobile phase consisted of phosphate-buffered saline ([PBS] 140 $\mathrm{mmol} / \mathrm{L} \mathrm{NaCl}, 9 \mathrm{mmol} / \mathrm{L} \mathrm{Na}_{2} \mathrm{HPO}_{4}, 1.3 \mathrm{mmol} / \mathrm{L} \mathrm{NaH} \mathrm{PO}_{4} ; \mathrm{pH}=$ 7.4; UMC Groningen) containing $10 \%$ methanol and $23 \mathrm{~g} / \mathrm{L} \mathrm{NaCl}$. The flow was $0.75 \mathrm{~mL} / \mathrm{min}$ and the UV-detector wavelengths were set to 220 and $280 \mathrm{~nm}$. The column performance was tested using a reference Bio-Rad gel-filtration standard. The retention time of bevacizumab was $16.7 \mathrm{~min}$. TCA precipitation was performed by mixing equal amounts of water for injection, 20\% trichloroacetic acid, and $3 \mu \mathrm{L}{ }^{89} \mathrm{Zr}$-bevacizumab reaction solution. The mixture was centrifuged and the radiochemical purity was determined by separation of the protein fraction and supernatant. The radioactivity in the fractions was measured by an LKB-1282-Compugamma-system (LKB Wallac).

ITLC was performed on silica gel strips using $0.15 \mathrm{~mol} / \mathrm{L}$ citrate buffer ( $\mathrm{pH}$ 6.0) as the mobile phase. Radioactivity was determined by an ITLC scanner (VCS-101; Veenstra Instruments).

\section{In Vitro Evaluation of Radiolabeled Compounds}

The stability of ${ }^{89} \mathrm{Zr}$-bevacizumab, ${ }^{89} \mathrm{Zr}$-IgG, and ${ }^{111} \mathrm{In}$-bevacizumab was determined by storing the final product $(1 \mathrm{mg}, 50$ $\mathrm{MBq})$ in $1 \mathrm{~mL}$ ammonium acetate $(50 \mathrm{mmol} / \mathrm{L})$ at $4^{\circ} \mathrm{C}$ and in $1 \mathrm{~mL}$ human serum (UMC Groningen) at $37^{\circ} \mathrm{C}$ for $7 \mathrm{~d}$. SE-HPLC, TCA, and ITLC procedures were performed 24, 72, and $168 \mathrm{~h}$ after labeling.

The binding properties for VEGF of ${ }^{89} \mathrm{Zr}$-bevacizumab, ${ }^{111} \mathrm{In}$ bevacizumab, and ${ }^{89} \mathrm{Zr}$-IgG were evaluated using a VEGF-coated enzyme-linked immunosorbent assay, comparable with the method described by Collingridge et al. (25). Briefly, recombinant human VEGF $_{165}$ (catalog no. 293-VE/CF; R\&D systems) was used as the 
target antigen and coated to Nunc-Immuno BreakApart plates (NUNC). Recombinant human VEGF $_{165}$ was diluted in PBS to a concentration of $5 \mu \mathrm{g} / \mathrm{mL}$. The solution was adjusted to $\mathrm{pH} 9.2-$ $9.5\left(50 \mathrm{mmol} / \mathrm{L} \mathrm{Na}_{2} \mathrm{CO}_{3}\right)$. Fifty microliters were added to the wells, incubated overnight at $4^{\circ} \mathrm{C}$, and then blocked with $1 \%$ human serum albumin (HSA; Sanquin) in PBS. After blocking, the plates were washed with $0.1 \%$ polysorbate 80 (Sigma-Aldrich) in PBS. ${ }^{89} \mathrm{Zr}$-Bevacizumab, ${ }^{111} \mathrm{In}$-bevacizumab, and ${ }^{89} \mathrm{Zr}$-IgG solutions were diluted in PBS (concentrations, 1.0-1.0 × 106 $\mathrm{ng} / \mathrm{mL}$ ), added to the wells, and incubated for $2 \mathrm{~h}$. Subsequently, the reaction solution was collected from the wells in 2 wash steps. Both the sustained radioactivity stacked to the antigen-coated wells and the collected reaction solution containing unbound radiolabeled antibody were measured by an LKB-1282-Compugamma-system. The percentage of binding was calculated as the fraction of radioactivity stacked to antigen-coated wells divided by the total amount of radioactivity added.

Competition experiments were performed by diluting bevacizumab standard solution $(25 \mathrm{mg} / \mathrm{mL})$ with PBS and adding an excess of unlabeled bevacizumab up to 500-fold. Glassware, materials, and solutions used for binding studies were pyrogenfree, metal-free, and coated with $2 \%$ HSA in PBS.

\section{Cell Culture and Animal Studies}

The human ovarian cancer cell line SKOV-3 was cultured in Dulbecco's modified Eagle medium (DMEM; UMC Groningen) with $4.5 \mathrm{~g} / \mathrm{mL}$ glucose and $10 \%$ fetal calf serum. SKOV-3 cells were chosen because of identified high VEGF production in vivo (26). Before animals were inoculated, the SKOV-3 cells were harvested by trypsinization and resuspended in culture medium and Matrigel (BD Bioscience). In vivo imaging and biodistribution experiments were conducted using male athymic mice (HSD; Athymic nude- $n u$ ) obtained from Harlan Nederland. At $8 \mathrm{wk}$ of age, the mice were injected subcutaneously with $1 \times 10^{6}$ SKOV-3 cells mixed equally with $0.1 \mathrm{~mL}$ Matrigel. Animals were used for in vivo studies when the tumor measured between 6 and $8 \mathrm{~mm}$ in diameter $\left( \pm 0.2 \mathrm{~cm}^{3}\right)$, approximately $2-3 \mathrm{wk}$ after inoculation.

All animal experiments were performed with isofluran inhalation anesthesia (induction, 3\%; maintenance, 1.5\%). ${ }^{89} \mathrm{Zr}$-Bevacizumab mice $(n=6)$ and ${ }^{89} \mathrm{Zr}$-IgG mice $(n=6)$ received an intravenous injection into the penile vein $(3.5 \pm 0.5 \mathrm{MBq}, 100 \pm 6 \mu \mathrm{g}$, $0.2 \mathrm{~mL}$ ). Animals were imaged using a microPET Focus 220 rodent scanner (Siemens Preclinical Solutions USA, Inc.). Static images of 30-min acquisition time were obtained at 24, 72, and $168 \mathrm{~h}$ after injection. Images were corrected for scatter and attenuation. Thereafter, microCT images were made using a MicroCAT II system (Siemens). Images were reconstructed and 3-dimensional regions of interest were drawn within the microCT images and transposed into microPET images for quantification, using the AsiPro 6.2.5.0. software fusion tool (Siemens). The total injected dose was calculated by decay correction of the activity present at $24 \mathrm{~h}$ after injection in the animal, at which time the clearance of the injected antibodies is almost negligible. Data are presented as the percentage injected dose per gram tissue $(\% \mathrm{ID} / \mathrm{g})$, assuming a tissue density of $1 \mathrm{~g} / \mathrm{cm}^{3}$. Animals were sacrificed after the last scan $(168 \mathrm{~h})$, and organs and tissues were excised, rinsed for residual blood, and weighed.

A combined dose of $50 \%{ }^{111} \mathrm{In}$-bevacizumab and $50 \%{ }^{89} \mathrm{Zr}$ bevacizumab $(2.0 \pm 0.5 \mathrm{MBq}$ each, $100 \pm 4 \mu \mathrm{g}$ in total, $0.2 \mathrm{~mL})$ was injected intravenously into the penile vein of animals used for ex vivo biodistribution studies. Mice were sacrificed at $24 \mathrm{~h}$ $(n=5), 72 \mathrm{~h}(n=5)$, and $168 \mathrm{~h}(n=5)$ after injection. Organs and tissues were excised, rinsed for residual blood, and weighed.

Samples and primed standards were counted for radioactivity in a calibrated well-type LKB-1282-Compu-gamma-system and corrected for physical decay. Biodistribution samples were measured using dual-isotope counting programs for ${ }^{89} \mathrm{Zr}$ and ${ }^{111} \mathrm{In}$, enabling comparison between ${ }^{89} \mathrm{Zr}$-bevacizumab and ${ }^{111} \mathrm{In}$-bevacizumab distribution. Tissue activity is expressed as the $\% \mathrm{ID} / \mathrm{g}$.

All animal experiments were approved by the Animal Experiments Committee of the University of Groningen.

\section{Immunohistochemistry}

Frozen-embedded tumors were stained with antibodies against mouse CD31 (PEGAM-1; BD Pharmingen) and human IgG (Dako). Anti-CD31 staining was performed to determine the microvessel density in the tumors of mice that received ${ }^{89} \mathrm{Zr}$ bevacizumab or ${ }^{89} \mathrm{Zr}$-IgG. Microvessel density was scored in 3 areas, defined as hot spot areas with the maximum number of microvessels, by using a calibrated grid. Antihuman IgG staining was performed to obtain more detailed information about the localization of the tracers. The slides were examined at $\times 200$ magnification.

\section{Statistical Analysis}

Data are presented as mean \pm SD. Statistical analysis was performed using the Mann-Whitney test, version 12 (SPSS). $P \leq$ 0.05 was considered significant.

\section{RESULTS}

\section{Radiolabeling, Quality Control}

Labeling with ${ }^{89} \mathrm{Zr}$ and ${ }^{111} \mathrm{In}$ resulted in labeling yields of $98.0 \% \pm 0.7 \%$ for ${ }^{89} \mathrm{Zr}$-bevacizumab and $96.6 \% \pm 0.5 \%$ for ${ }^{111} \mathrm{In}$-bevacizumab and $95.4 \% \pm 0.3 \%$ for ${ }^{89} \mathrm{Zr}-\mathrm{IgG}$, without purification. Specific activity was $58 \mathrm{MBq} / \mathrm{mg}$ for ${ }^{89} \mathrm{Zr}$-bevacizumab and $50 \mathrm{MBq} / \mathrm{mg}$ for ${ }^{111} \mathrm{In}$-bevacizumab. No impurities were detected. These results demonstrate that bevacizumab and human IgG can be labeled with high labeling efficiency with ${ }^{89} \mathrm{Zr}$ and ${ }^{111} \mathrm{In}$.

\section{In Vitro Evaluation of Radiolabeled Compounds}

${ }^{89} \mathrm{Zr}$-Bevacizumab, stored at $4^{\circ} \mathrm{C}$ in ammonium acetate and at $37^{\circ} \mathrm{C}$ in serum for $1 \mathrm{wk}$, displayed a small decrease $(6 \%)$ in protein-bound radioactivity after $168 \mathrm{~h} .{ }^{111} \mathrm{In}-$ Bevacizumab and ${ }^{89} \mathrm{Zr}$-IgG showed an even smaller decrease $(\leq 5 \%)$ in protein-bound radioactivity. The stability of the labeled products ensures optimal quantitative measurement and imaging during $1 \mathrm{wk}$.

Radiolabeled bevacizumab showed adequate VEGF binding, irrespective of the type of radiolabeling. Binding experiments of ${ }^{89} \mathrm{Zr}$-bevacizumab resulted in $54.0 \% \pm$ $3.7 \%$ binding. A competition assay with excess unlabeled bevacizumab ( $\geq 500$ fold) could almost completely block ${ }^{89} \mathrm{Zr}$-bevacizumab binding $(<5 \%)$, comparable with $4 \%-$ $8 \%$ nonspecific binding for ${ }^{89} \mathrm{Zr}-\mathrm{IgG}$. Experiments with ${ }^{111}$ In-bevacizumab showed $56.9 \% \pm 0.7 \%$ binding. Competition experiments with $50 \%$ radiolabeled and unlabeled bevacizumab (1:1) resulted in an approximately $50 \%$ decrease of the initial binding of radiolabeled bevacizumab, 
FIGURE 1. Coronal CT image (A) with clear subcutaneous localization of SKOV3 tumor (arrow). Fusion of microPET and CT images (B) (168 h after injection) enables adequate quantitative measurement of ${ }^{89} \mathrm{Zr}$-bevacizumab in the tumor.

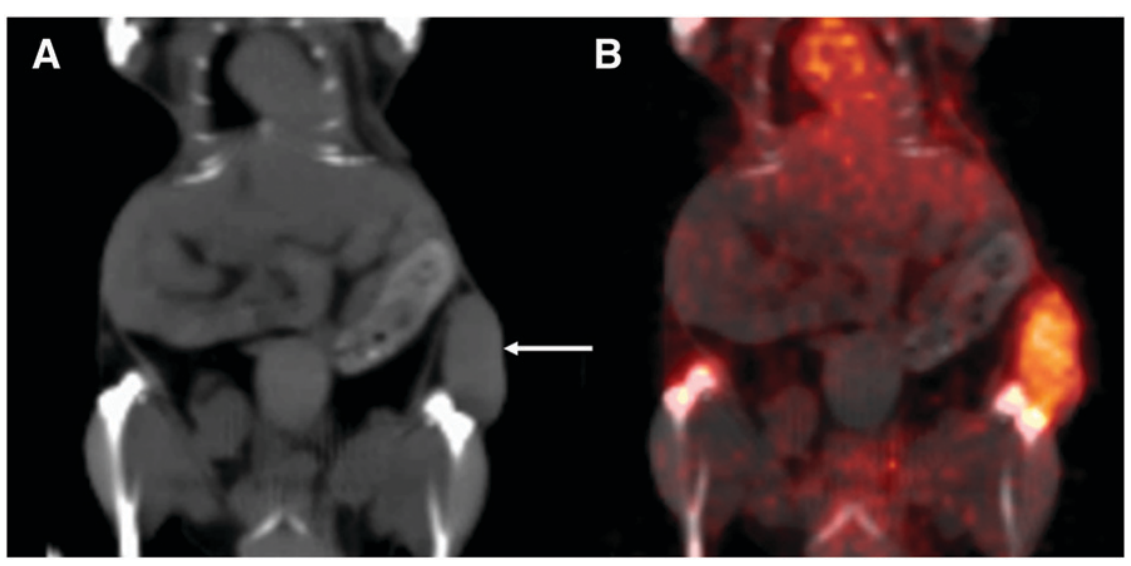

demonstrating almost equal binding characteristics of radiolabeled and unlabeled bevacizumab. These results ensure adequate VEGF binding by ${ }^{89} \mathrm{Zr}$ - and ${ }^{111} \mathrm{In}$-bevacizumab.

\section{Animal Studies}

microPET and microCT fusion enabled excellent tumor visualization and quantification (Fig. 1). microPET images showed uptake in well-perfused organs and plasma at $24 \mathrm{~h}$ after injection, which declined at later time points. Increasing tumor-to-blood ratio resulted in clear tumor localization of ${ }^{89} \mathrm{Zr}$-bevacizumab from $72 \mathrm{~h}$ onward after injection (Fig. 2). In addition, uptake of ${ }^{89} \mathrm{Zr}$-bevacizumab was predominantly seen in liver and spleen. Quantitative measurement of ${ }^{89} \mathrm{Zr}$-bevacizumab in the tumor by microPET was significantly higher compared with human ${ }^{89} \mathrm{Zr}-\mathrm{IgG}-$ namely, $7.38 \pm 2.06 \% \mathrm{ID} / \mathrm{g}$ compared with $3.39 \pm 1.16$ $\% \mathrm{ID} / \mathrm{g}(P=0.011)$ at $168 \mathrm{~h}$ after injection (Fig. 3). Similar results were seen in biodistribution experiments when tumors were excised and counted in a $\gamma$-counter: Tumor uptake was $6.82 \pm 1.80 \% \mathrm{ID} / \mathrm{g}$ for ${ }^{89} \mathrm{Zr}$-bevacizumab compared with $2.87 \pm 0.48 \% \mathrm{ID} / \mathrm{g}$ for human ${ }^{89} \mathrm{Zr}-\operatorname{IgG}(P=$ 0.006) (Fig. 3). Beside tumor uptake, ex vivo biodistribution experiments showed an equal organ distribution pattern for ${ }^{89} \mathrm{Zr}$-bevacizumab and ${ }^{89} \mathrm{Zr}$-IgG (Fig. 4), except for kidney uptake, which was significantly higher for ${ }^{89} \mathrm{Zr}-\mathrm{IgG}$ compared with ${ }^{89} \mathrm{Zr}$-bevacizumab $(P=0.004)$.
The ex vivo biodistribution for ${ }^{89} \mathrm{Zr}$-bevacizumab and ${ }^{111}$ In-bevacizumab was similar at 24, 72, and $168 \mathrm{~h}$ after injection (Table 1), demonstrating that both tracers could be used for VEGF imaging.

\section{Immunohistochemistry}

There was no difference in microvessel density or blood vessel distribution pattern between the tumors of the ${ }^{89} \mathrm{Zr}$ bevacizumab- and the ${ }^{89} \mathrm{Zr}$-IgG-injected mice. Antihuman IgG staining was seen primarily in the blood vessels of the tumor (Fig. 5).

\section{DISCUSSION}

${ }^{89} \mathrm{Zr}$ and ${ }^{111} \mathrm{In}$ labeling of bevacizumab resulted in high labeling efficiencies and adequate preservation of VEGFbinding properties. Tumor uptake of ${ }^{89} \mathrm{Zr}$-bevacizumab and ${ }^{111}$ In-bevacizumab were both significantly higher compared with that of the control ${ }^{89} \mathrm{Zr}$-IgG. Tumor uptake of ${ }^{89} \mathrm{Zr}$ bevacizumab and ${ }^{111}$ In-bevacizumab was already high at $24 \mathrm{~h}$ after injection, increasing in time with clear tumor visualization from $72 \mathrm{~h}$ onward after injection. These results demonstrate that radiolabeled bevacizumab is a potential new tracer for noninvasive imaging of VEGF in the microenvironment of the tumor.

Two human anti-VEGF antibodies, VG76e and HumMV833, have been used previously for noninvasive
FIGURE 2. Coronal planes of microPET images $24 \mathrm{~h}(\mathrm{~A}), 72 \mathrm{~h}(\mathrm{~B})$, and $168 \mathrm{~h}(\mathrm{C})$ after injection of ${ }^{89} \mathrm{Zr}$-bevacizumab. At $24 \mathrm{~h}$, most uptake is in well-perfused organs. In time, relative uptake in the tumor (arrow) increases.

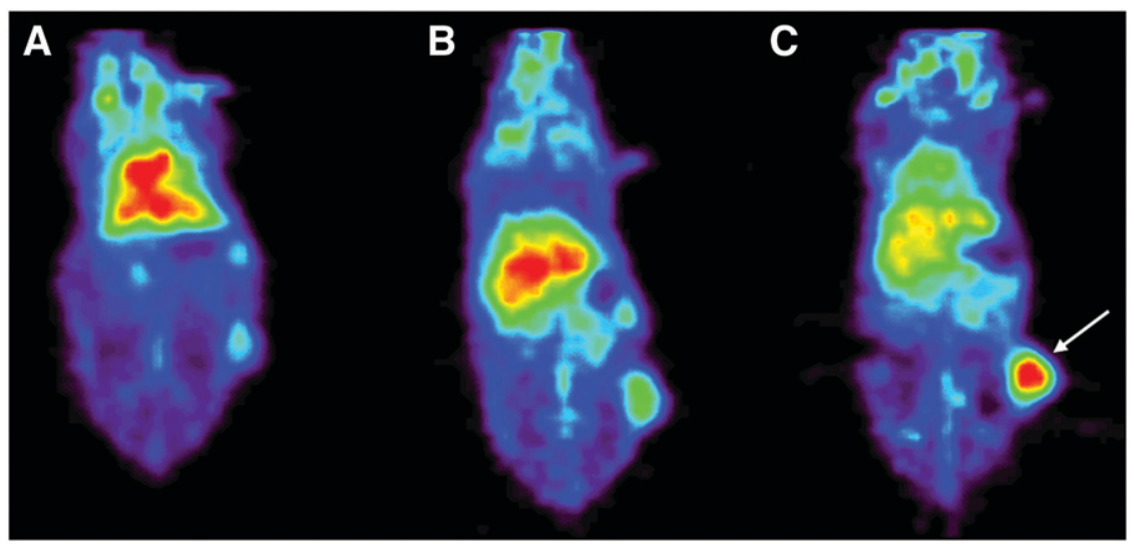




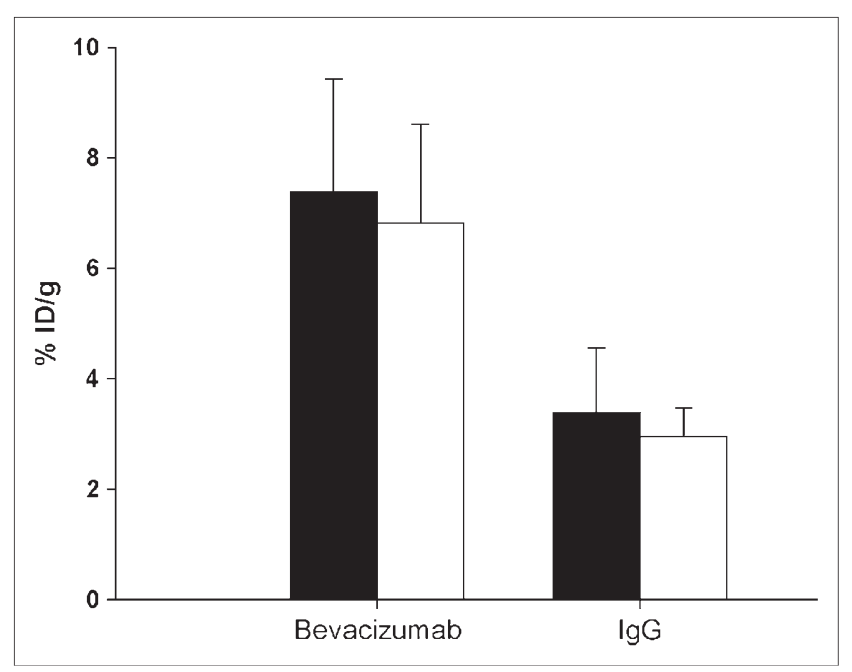

FIGURE 3. Comparison of tumor uptake of ${ }^{89} \mathrm{Zr}$-bevacizumab and control ${ }^{89} \mathrm{Zr}$-IgG as determined by noninvasive microPET imaging $(\square)(n=6)$ and by $\gamma$-counting of excised tumors $(\square)$ $(n=6) 168 \mathrm{~h}$ after injection. Data are presented as $\% \mathrm{ID} / \mathrm{g} \pm \mathrm{SD}$, assuming a tissue density of $1 \mathrm{~g} / \mathrm{cm}^{3}$.

VEGF imaging (25,27). ${ }^{125} \mathrm{I}$ - and ${ }^{124} \mathrm{I}$-labeled VG76e-an IgG1 mouse monoclonal anti-VEGF antibody that recognizes the 121, 165, and 189 isoforms of human VEGF-Ashowed specific tumor targeting in a human fibrosarcoma xenograft mouse model. Maximum uptake was seen after $24 \mathrm{~h}$, declining at $48 \mathrm{~h}$ after injection. These results are in contrast to our results, in which radiolabeled bevacizumab did not show tumor clearance up to $168 \mathrm{~h}$ after injection, which increases the available time for imaging. Jayson et al. (27) used ${ }^{124} \mathrm{I}-\mathrm{HuMV} 833$, a humanized monoclonal $\mathrm{IgG}_{\mathrm{k}}$ antibody that binds $\mathrm{VEGF}_{121}$ and $\mathrm{VEGF}_{165}$, to perform PET studies on patients with various progressive solid tumors. Tumor uptake of ${ }^{124}$ I-HuMV833 was highly variable between and within patients. For example, there was high uptake of ${ }^{124}$ I-HuMV833 in an ovarian tumor and low uptake in a poorly vascularized metastasis from colon cancer. These differences may represent the variation in available target for the antibody between tumor types and lesions, which could have implications for anti-VEGF therapy (27). The monoclonal antibody bevacizumab that we used in this study, with high binding affinity to all VEGF-A isoforms and proven clinical effectiveness, is more attractive and accessible for this approach. Another point of application in the evaluation of anti-VEGF therapy could be VEGF-receptor imaging. Cai et al. described the development of VEGF-receptor imaging with ${ }^{64} \mathrm{Cu}$-DOTAVEGF $_{121}$ (DOTA is 1,4,7,10-tetraazacyclododecane- $N, N^{\prime}$, $N^{\prime \prime}, N^{\prime \prime \prime}$-tetraacetic acid) (28). They showed that VEGFreceptor imaging with ${ }^{64} \mathrm{Cu}-\mathrm{DOTA}-\mathrm{VEGF}_{121}$ corresponded with immunohistochemical analysis in a human glioblastoma-bearing mouse model. At this point, the correlation between levels of VEGF expression and VEGF-receptor expression is not elucidated. Therefore, in vivo VEGFreceptor imaging with ${ }^{64} \mathrm{Cu}-\mathrm{DOTA}-\mathrm{VEGF}_{121}$ might facilitate the evaluation of VEGF-receptor expression, whereas radiolabeled bevacizumab could be used to evaluate VEGF levels. Both techniques could be complementary in the clinical evaluation of antiangiogenic therapy.

In the present study, we have shown that microPET and CT imaging, using ${ }^{89} \mathrm{Zr}$-bevacizumab, not only allowed imaging up to $168 \mathrm{~h}$ after injection but also enabled quantitative measurement of the tracer in the tumor. Tumor uptake values as assessed by noninvasive microPET quantification of ${ }^{89} \mathrm{Zr}$-bevacizumab were identical to uptake values as assessed by $\gamma$-counting of excised tumors, demonstrating the potential role of PET quantification beside in vivo visualization. The biodistribution of bevacizumab was investigated earlier by Lin et al. in rabbits with ${ }^{125}$ I-labeled bevacizumab; however, the uptake of bevacizumab was only investigated in normal tissues (29). The results were similar to

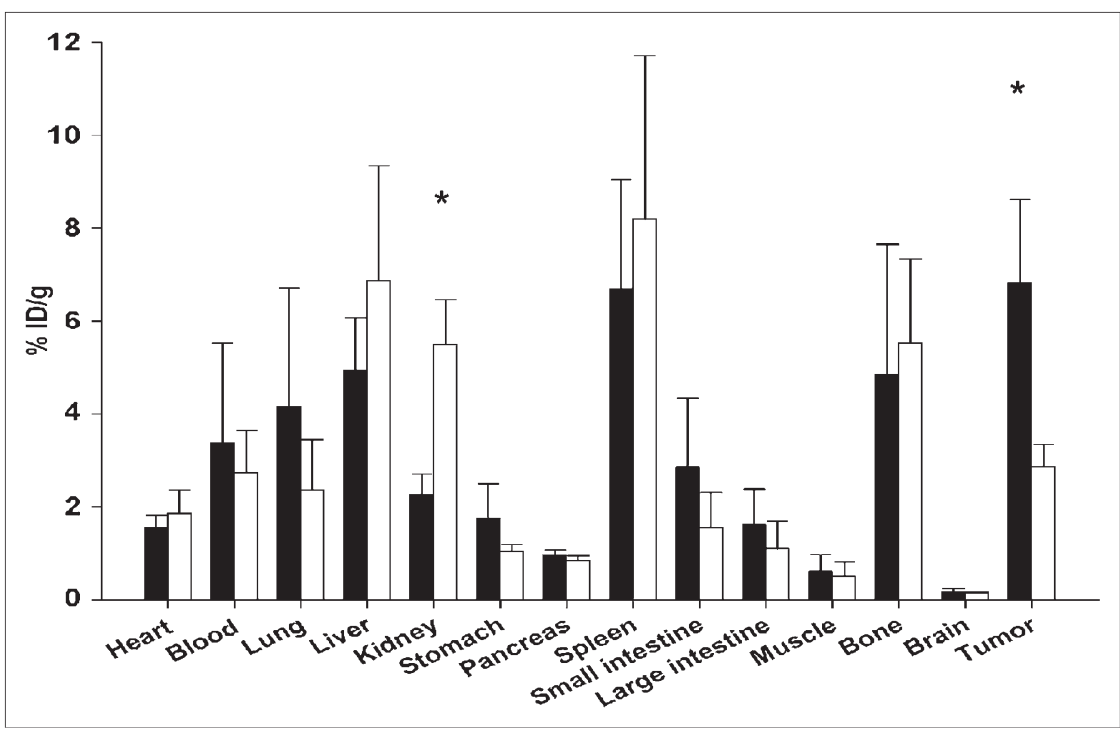

FIGURE 4. Ex vivo biodistribution of ${ }^{89} \mathrm{Zr}$-bevacizumab $(n=6)(\square)$ and control ${ }^{89} \mathrm{Zr}-\lg \mathrm{g}(n=6)(\square) 168 \mathrm{~h}$ after injection. Uptake of ${ }^{89} \mathrm{Zr}$-bevacizumab within the tumor is significantly higher than that of control ${ }^{89} \mathrm{Zr}$-lgG $(P=0.006)$. Data are presented as $\% \mathrm{ID} / \mathrm{g} \pm \mathrm{SD}$. ${ }^{*} P \leq 0.05$. 
TABLE 1

Ex Vivo Biodistribution of Mice Receiving ${ }^{89} \mathrm{Zr}$-Bevacizumab and ${ }^{111} \mathrm{In}$-Bevacizumab

\begin{tabular}{|c|c|c|c|c|c|c|}
\hline \multirow[b]{2}{*}{ Biodistribution } & \multicolumn{2}{|c|}{$24 \mathrm{~h}(n=5)$} & \multicolumn{2}{|c|}{$72 \mathrm{~h}(n=5)$} & \multicolumn{2}{|c|}{168 h $(n=5)$} \\
\hline & ${ }^{89} \mathrm{Zr}$-Bev. & ${ }^{111}$ In-Bev. & 89Zr-Bev. & ${ }^{111}$ In-Bev. & 89Zr-Bev. & ${ }^{111}$ In-Bev. \\
\hline Heart & $3.43 \pm 0.99$ & $4.34 \pm 1.22$ & $2.31 \pm 0.93$ & $3.60 \pm 0.95$ & $2.11 \pm 0.66$ & $3.09 \pm 1.30$ \\
\hline Blood & $9.54 \pm 5.12$ & $11.87 \pm 6.19$ & $5.60 \pm 3.20$ & $8.50 \pm 1.84$ & $3.75 \pm 2.24$ & $5.99 \pm 2.01$ \\
\hline Lung & $6.22 \pm 4.39$ & $7.58 \pm 4.86$ & $3.50 \pm 1.57$ & $5.24 \pm 1.88$ & $2.75 \pm 0.84$ & $3.56 \pm 0.89$ \\
\hline Liver & $5.01 \pm 1.27$ & $4.91 \pm 0.95$ & $3.98 \pm 1.29$ & $5.17 \pm 1.22$ & $3.93 \pm 1.49$ & $3.30 \pm 0.59$ \\
\hline Kidney & $3.94 \pm 0.91$ & $4.35 \pm 1.01$ & $2.51 \pm 0.93$ & $3.36 \pm 0.56$ & $2.45 \pm 0.44$ & $2.82 \pm 0.63$ \\
\hline Stomach & $2.01 \pm 0.25$ & $2.37 \pm 0.40$ & $1.33 \pm 0.50$ & $1.94 \pm 0.66$ & $1.15 \pm 0.45$ & $1.30 \pm 0.36$ \\
\hline Pancreas & $1.83 \pm 0.30$ & $2.33 \pm 0.35$ & $0.99 \pm 0.42$ & $1.49 \pm 0.27$ & $0.93 \pm 0.17$ & $1.06 \pm 0.19$ \\
\hline Spleen & $4.52 \pm 1.92$ & $5.74 \pm 2.76$ & $3.22 \pm 1.41$ & $5.13 \pm 2.91$ & $6.07 \pm 4.80$ & $6.37 \pm 4.54$ \\
\hline Small intestine & $3.24 \pm 2.11$ & $4.10 \pm 2.72$ & $1.54 \pm 0.99$ & $2.40 \pm 1.79$ & $2.03 \pm 1.86$ & $1.91 \pm 1.35$ \\
\hline Large intestine & $2.09 \pm 0.45$ & $2.57 \pm 0.64$ & $1.12 \pm 0.41$ & $1.64 \pm 0.60$ & $1.63 \pm 1.12$ & $1.48 \pm 0.64$ \\
\hline Muscle & $1.02 \pm 0.16$ & $1.23 \pm 0.15$ & $0.60 \pm 0.23$ & $0.90 \pm 0.08$ & $0.61 \pm 0.20$ & $0.82 \pm 0.38$ \\
\hline Bone & $3.00 \pm 0.87$ & $3.05 \pm 0.77$ & $2.77 \pm 1.93$ & $2.29 \pm 1.17$ & $5.75 \pm 4.01$ & $2.48 \pm 1.49$ \\
\hline Brain & $0.33 \pm 0.09$ & $0.41 \pm 0.11$ & $0.21 \pm 0.09$ & $0.31 \pm 0.05$ & $0.22 \pm 0.06$ & $0.26 \pm 0.09$ \\
\hline Tumor & $4.85 \pm 1.55$ & $6.23 \pm 2.03$ & $4.36 \pm 2.80$ & $6.17 \pm 1.30$ & $6.97 \pm 2.41$ & $7.74 \pm 1.99$ \\
\hline
\end{tabular}

Bev. = bevacizumab.

Data presented as $\% \mathrm{ID} / \mathrm{g} \pm \mathrm{SD}$.

our findings, with high uptake in heart and blood after $24 \mathrm{~h}$, decreasing in time, and high uptake in liver and spleen at later time points. Our study additionally demonstrated that the tumor is a major compartment, besides plasma, liver, and spleen, in bevacizumab distribution.

We used $100 \mu \mathrm{g}$ of ${ }^{89} \mathrm{Zr}$-bevacizumab for imaging and biodistribution studies. Smaller doses of bevacizumab could result in accelerated and increased clearance of ${ }^{89} \mathrm{Zr}$ - and ${ }^{111}$ In-bevacizumab in the absence of $\operatorname{IgG}$ production by the nude mice (30). As a control, we used ${ }^{89} \mathrm{Zr}$-labeled human IgG to provide evidence that ${ }^{89} \mathrm{Zr}$-bevacizumab uptake is due to specific targeting in the tumor and is not caused by blood perfusion and passive diffusion within the tumor. Another frequently used approach to show specificity is blocking with an excess of the unlabeled agent (25).

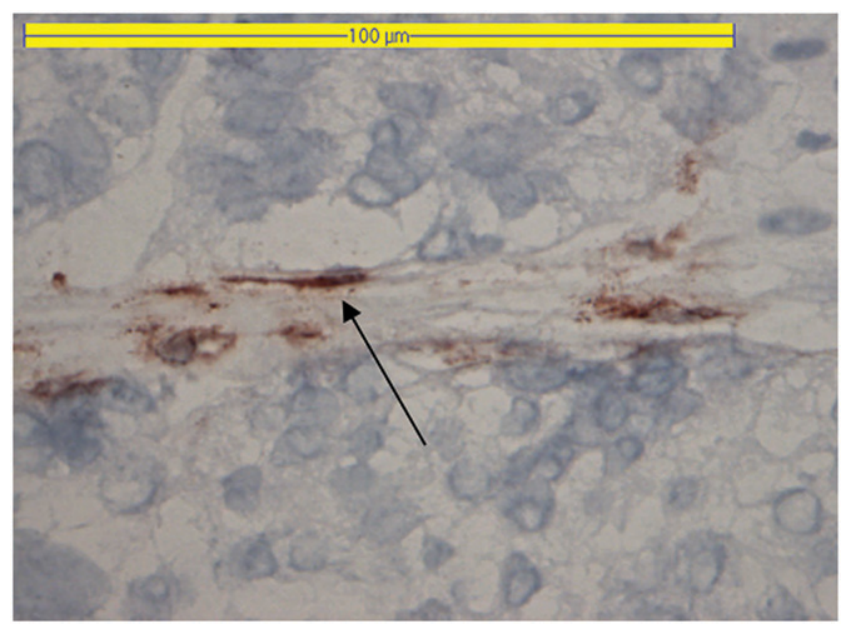

FIGURE 5. Antihuman lgG staining (arrow) in a tumor slice from mice receiving ${ }^{89} \mathrm{Zr}$-bevacizumab.
However, the use of an excess of unlabeled bevacizumab (up to 10-fold) could induce functional changes and, in this way, change the perfusion and uptake of radiolabeled bevacizumab in the tumor at later time points (31). Vascular changes after a single infusion of bevacizumab have been described earlier. Willett et al. showed a decreased microvessel density in rectal cancer patients already at $12 \mathrm{~d}$ after a single infusion of bevacizumab (31). To exclude that these effects were present in our study - due to $100 \mu \mathrm{g}$ of radiolabeled bevacizumab-the microvessel density was determined in the tumors of the ${ }^{89} \mathrm{Zr}$-bevacizumab- and ${ }^{89} \mathrm{Zr}-\mathrm{IgG}-$ injected mice. There was no difference in microvessel density between the tumors of the 2 groups. These findings substantiate the result that high uptake of radiolabeled bevacizumab is due to specific targeting and not a result of vascular changes.

To obtain more detailed information with regard to the localization of radiolabeled bevacizumab (humanized IgG1 antibody) in the tumor, we performed antihuman $\operatorname{IgG}$ staining. Antihuman IgG was predominantly present in the blood vessels of the tumors. Cell-surface binding of antihuman $\operatorname{IgG}$ was not clearly evident. These results suggested that radiolabeled bevacizumab binds primarily to VEGF present in the blood vessels of the tumor. Binding to VEGF localized in the extracellular matrix of tumor cells could not be demonstrated.

In the present study, we used 2 isotopes for the development of radiolabeled bevacizumab. The PET isotope ${ }^{89} \mathrm{Zr}$ has good characteristics for antibody imaging. The relatively long half-life of $3.27 \mathrm{~d}$ makes imaging possiblematching the pharmacokinetics of bevacizumab (half-life $=$ 17-21 d) — combined with the advantages of high-resolution PET imaging. Borjesson et al. described the first clinical application of ${ }^{89} \mathrm{Zr}$, using labeled U36, an anti-CD44v6 antibody, 
to detect lymph node metastases in head and neck cancer patients (23). ${ }^{89} \mathrm{Zr}$ will be commercially available soon. ${ }^{89} \mathrm{Zr}$ might give a relatively high radiation exposure to patients, due to the high-energy, high-abundance $\gamma$-ray (909 $\mathrm{keV}, 99.9 \%)$ and low-abundance $\beta^{+}(22 \%)$ emitted during the decay of ${ }^{89} \mathrm{Zr}$ (32). However, the clinical dose for adequate ${ }^{89} \mathrm{Zr}$-bevacizumab PET has yet to be established. Increased sensitivity of new-generation PET cameras could further reduce the radiation exposure. As an alternative for PET, we also developed ${ }^{111}$ In-labeled bevacizumab for SPECT, as we described previously for trastuzumab, a HER-2 neu antibody (20). The ex vivo biodistribution results for ${ }^{111}$ In-bevacizumab were similar to those of ${ }^{89} \mathrm{Zr}$-bevacizumab. Both ${ }^{111}$ In-bevacizumab and ${ }^{89} \mathrm{Zr}$-bevacizumab can be used clinically for noninvasive in vivo VEGF imaging, although the feasibility of ${ }^{111}$ In-bevacizumab for in vivo quantification was not established by this study.

\section{CONCLUSION}

This study illustrates the potential of ${ }^{89} \mathrm{Zr}$-bevacizumab and ${ }^{111}$ In-bevacizumab as a specific VEGF tracer, with excellent in vivo quantitative measurement of ${ }^{89} \mathrm{Zr}$-bevacizumab. Noninvasive measurement of VEGF levels in the tumor could provide essential information in the evaluation of antiangiogenic therapy. This could lead to better understanding and patient-tailored therapy.

\section{REFERENCES}

1. Folkman J. What is the evidence that tumors are angiogenesis dependent? J Natl Cancer Inst. 1990;82:4-6.

2. Folkman J, Klagsbrun M. Angiogenic factors. Science. 1987;235:442-447.

3. Ferrara N, Davis-Smyth T. The biology of vascular endothelial growth factor. Endocr Rev. 1997;18:4-25.

4. Ferrara N. Vascular endothelial growth factor: basic science and clinical progress. Endocr Rev. 2004;25:581-611.

5. Shibuya M. Vascular endothelial growth factor receptor-2: its unique signaling and specific ligand, VEGF-E. Cancer Sci. 2003;94:751-756.

6. Crawford SE. Vascular interference: a blockade to tumor epithelial growth. Hepatology. 2004;39:1491-1494.

7. Ferrara N. Role of vascular endothelial growth factor in regulation of physiological angiogenesis. Am J Physiol Cell Physiol. 2001;280:C1358-C1366.

8. Gerber HP, Ferrara N. Pharmacology and pharmacodynamics of bevacizumab as monotherapy or in combination with cytotoxic therapy in preclinical studies. Cancer Res. 2005;65:671-680.

9. Akbulut H, Altuntas F, Akbulut KG, et al. Prognostic role of serum vascular endothelial growth factor, basic fibroblast growth factor and nitric oxide in patients with colorectal carcinoma. Cytokine. 2002;20:184-190.

10. Shimanuki Y, Takahashi K, Cui R, et al. Role of serum vascular endothelial growth factor in the prediction of angiogenesis and prognosis for non-small cell lung cancer. Lung. 2005;183:29-42.
11. Yen L, You XL, Al Moustafa AE, et al. Heregulin selectively upregulates vascular endothelial growth factor secretion in cancer cells and stimulates angiogenesis. Oncogene. 2000;19:3460-3469.

12. Bergsland EK. Update on clinical trials targeting vascular endothelial growth factor in cancer. Am J Health Syst Pharm. 2004;61(suppl 5):S12-S20.

13. Wang Y, Fei D, Vanderlaan M, Song A. Biological activity of bevacizumab, a humanized anti-VEGF antibody in vitro. Angiogenesis. 2004;7:335-345.

14. Yuan F, Chen Y, Dellian M, Safabakhsh N, Ferrara N, Jain RK. Time-dependent vascular regression and permeability changes in established human tumor xenografts induced by an anti-vascular endothelial growth factor/vascular permeability factor antibody. Proc Natl Acad Sci USA. 1996;93:14765-14770.

15. Fox WD, Higgins B, Maiese KM, et al. Antibody to vascular endothelial growth factor slows growth of an androgen-independent xenograft model of prostate cancer. Clin Cancer Res. 2002;8:3226-3231.

16. Hurwitz H, Fehrenbacher L, Novotny W, et al. Bevacizumab plus irinotecan, fluorouracil, and leucovorin for metastatic colorectal cancer. $N$ Engl J Med. 2004;350:2335-2342.

17. Sandler A, Gray R, Perry MC, et al. Paclitaxel-carboplatin alone or with bevacizumab for non-small-cell lung cancer. N Engl J Med. 2006;355:25422550 .

18. Park JE, Keller GA, Ferrara N. The vascular endothelial growth factor (VEGF) isoforms: differential deposition into the subepithelial extracellular matrix and bioactivity of extracellular matrix-bound VEGF. Mol Biol Cell. 1993;4:13171326.

19. Jain RK, Duda DG, Clark JW, Loeffler JS. Lessons from phase III clinical trials on anti-VEGF therapy for cancer. Nat Clin Pract Oncol. 2006;3:24-40.

20. Lub-De Hooge MN, Kosterink JG, Perik PJ, et al. Preclinical characterisation of ${ }^{111}$ In-DTPA-trastuzumab. Br J Pharmacol. 2004;143:99-106.

21. Perik PJ, Lub-De Hooge MN, Gietema JA, et al. Indium-111-labeled trastuzumab scintigraphy in patients with human epidermal growth factor receptor 2-positive metastatic breast cancer. J Clin Oncol. 2006;24:2276-2282.

22. Verel I, Visser GW, Boerman OC, et al. Long-lived positron emitters zirconium89 and iodine-124 for scouting of therapeutic radioimmunoconjugates with PET. Cancer Biother Radiopharm. 2003;18:655-661.

23. Borjesson PK, Jauw YW, Boellaard R, et al. Performance of immuno-positron emission tomography with zirconium-89-labeled chimeric monoclonal antibody U36 in the detection of lymph node metastases in head and neck cancer patients. Clin Cancer Res. 2006;12:2133-2140.

24. Ruegg CL, Anderson-Berg WT, Brechbiel MW, Mirzadeh S, Gansow OA, Strand M. Improved in vivo stability and tumor targeting of bismuth-labeled antibody. Cancer Res. 1990;50:4221-4226.

25. Collingridge DR, Carroll VA, Glaser M, et al. The development of $\left[{ }^{124} I\right]$ iodinatedVG76e: a novel tracer for imaging vascular endothelial growth factor in vivo using positron emission tomography. Cancer Res. 2002;62:5912-5919.

26. Keyes KA, Mann L, Teicher B, Alvarez E. Site-dependent angiogenic cytokine production in human tumor xenografts. Cytokine. 2003;21:98-104.

27. Jayson GC, Zweit J, Jackson A, et al. Molecular imaging and biological evaluation of HuMV833 anti-VEGF antibody: implications for trial design of antiangiogenic antibodies. J Natl Cancer Inst. 2002;94:1484-1493.

28. Cai W, Chen K, Mohamedali KA, et al. PET of vascular endothelial growth factor receptor expression. J Nucl Med. 2006;47:2048-2056.

29. Lin YS, Nguyen C, Mendoza JL, et al. Preclinical pharmacokinetics, interspecies scaling, and tissue distribution of a humanized monoclonal antibody against vascular endothelial growth factor. J Pharmacol Exp Ther. 1999;288:371-378.

30. Sharkey RM, Natale A, Goldenberg DM, Mattes MJ. Rapid blood clearance of immunoglobulin G2a and immunoglobulin G2b in nude mice. Cancer Res. 1991;51:3102-3107.

31. Willett CG, Boucher Y, di Tomaso E, et al. Direct evidence that the VEGFspecific antibody bevacizumab has antivascular effects in human rectal cancer. Nat Med. 2004;10:145-147.

32. Zalutsky MR. Potential of immuno-positron emission tomography for tumor imaging and immunotherapy planning. Clin Cancer Res. 2006;12:1958-1960. 